\title{
IMPLEMENTASI SISTEM INFORMASI GEOGRAFIS (SIG) PADA PENYEBARAN LOKASI KULIAH KERJA NYATA (KKN)
}

\author{
Alfi Andryan Suryadi \\ Fakultas Teknik, Program Studi Teknik Informatika \\ Universitas Siliwangi \\ Email: alfi.andryan@student.unsil.ac.id \\ Husni Mubarok \\ Fakultas Teknik, Program Studi Teknik Informatika \\ Universitas Siliwangi \\ Email: husni.mubarok@unsil.ac.id \\ Rohmat Gunawan \\ Fakultas Teknik, Program Studi Teknik Informatika \\ Universitas Siliwangi \\ Email: rohmatgunawan@unsil.ac.id
}

\begin{abstract}
ABSTRAK
Kuliah Kerja Nyata (KKN) merupakan salah satu bentuk kegiatan yang memadukan unsur Tri Dharma Pendidikan Tinggi dalam upaya meningkatkan isi dan bobot pendidikan bagi mahasiswa. Kegiatan KKN juga telah dilaksanakan oleh Lembaga Penelitian dan Pengabdian Masyarakat (LPPM) Universitas XYZ. Tetapi, masih ada permasalahan dalam penyelenggaraan kegiatan KKN tersebut, diantaranya sulitnya pihak LPPM dalam memetakan lokasi KKN secara visual, sulitnya Dosen Pembimbing Lapangan (DPL) dan mahasiswa mengetahui lokasi desa tempat KKN secara visual serta belum tersedianya informasi jalur atau rute menuju lokasi KKN. Agar pemetaan lokasi KKN secara visual dapat dilakukan maka, diusulkan untuk dikembangkan Sistem Informasi Geografis (SIG) pemetaan lokasi KKN. Dalam pengembangan SIG pemetaan lokasi KKN ini digunakan metode prototype yang terdiri dari: Communication, Quick Plan, Modelling Quick Design, Contruction of Prototype dan Deployment Delivery and Feedack. Hasil dari penelitian ini, berdasarkan data KKN tahun 2017, SIG yang dikembangkan telah dapat menyediakan informasi pemetaan lokasi KKN sebanyak 91 desa, yang dapat diakses oleh 281 DPL dan 2178 mahasiwa peserta KKN, serta dapat menampilkan lokasi rute menuju desa lokasi KKN beserta koordinat lokasi setiap desa.
\end{abstract}

Kata kunci: KKN, SIG, lokasi, visual.

\begin{abstract}
Kuliah Kerja Nyata (KKN) is a programme that combined Tri Dharma pendidikan tinggi, they are education, teaching and dedication to the society. KKN is held by the university in the effort to improve the content and education quality for the students and to get the bigger plus point in the university. KKN programme has also been held by Lembaga Penelitian dan Pengabdian Masyarakat (LPPM) of Siliwangi University. But, there is a problem in holding KKN programme, such as the lack of LPPM in mapping and giving information about KKN location visually, the lack of Dosen Pembimbing Lapangan (DPL) and students to know the location visually and the lack of getting information about track and route to reach KKN location. In order to mapping the location of KKN visually can be done then, it is proposed to developed Geographic Information System (GIS) mapping of KKN location. In the development of GIS mapping the location of KKN is used prototype method which consists of: Communication, Quick Plan, Quick Design Modeling, Contruction of Prototype and Deployment Delivery and Feedack. The results of this study, based on KKN data in 2017, developed GIS has been able to provide information mapping locations KKN 91 villages, which can be accessed by 281 DPL and 2178 students KKN, and can display the location of the route to the village location KKN and coordinate the location of each village.
\end{abstract}

Keywords: GIS, KKN, location, visual. 


\section{PENDAHULUAN}

\subsection{Latar Belakang}

Kuliah Kerja Nyata (KKN) adalah bentuk kegiatan yang memadukan unsur Tri Dharma Pendidikan Tinggi, yaitu Pendidikan dan Pengajaran, Penelitian dan Pengabdian kepada Masyarakat [4]. KKN dilaksanakan oleh perguruan tinggi dalam upaya meningkatkan isi dan bobot pendidikan bagi mahasiswa dan untuk mendapatkan nilai tambah yang lebih besar pada pendidikan tinggi.

Kegiatan Kuliah Kerja Nyata (KKN) juga telah dilaksanakan oleh Lembaga Penelitian dan Pengabdian Masyarakat (LPPM) Universitas XYZ. Akan tetapi, masih ada permasalahan dalam penyelenggaraan kegiatan KKN tersebut. diataranya sulitnya pihak LPPM dalam memetakan lokasi KKN secara visual. Pemetaan lokasi KKN yang dilakukan saat ini yaitu, berupa tabel yang terdiri dari nama kecamatan, nama desa dan nama kelompok mahasiswa yang akan melaksanakan kegiatan KKN, serta daftar Dosen Pembimbing Lapangan (DPL) untuk setiap kelompok KKN. Masalah lainnya yaitu sulitnya Dosen Pembimbing Lapangan (DPL) dan mahasiswa mengetahui lokasi desa tempat KKN secara visual, serta sulitnya mendapatkan informasi jalur atau rute menuju lokasi tempat KKN. Sehingga sebelum pelaksanan pemberangkatan ke lokasi $\mathrm{KKN}$, terkadang mahasiswa harus melakukan survei ke lokasi KKN, supaya dapat mengetahui informasi rute menuju lokasi tempat KKN yang sangat diperlukan pada saat pemberangkatan, hal ini tentunya akan membutuhkan waktu dan biaya.

\subsection{Landasan Teori}

\subsubsection{Google Maps API}

Google Maps adalah layanan berbasis web yang menyediakan informasi mendetail tentang wilayah geografis dan situs di seluruh dunia. Selain peta jalan konvensional, Google Maps menawarkan pemandangan udara dan satelit dari banyak tempat. Di beberapa kota, Google Maps menawarkan tampilan jalan yang terdiri dari foto-foto yang diambil dari kendaraan [8]. Pada Google Maps API terdapat 4 jenis pilihan model peta yang disediakan oleh Google [7], diantaranya: Roadmap, Satellite, Terrain dan Hybrid.

\subsubsection{Kuliah Kerja Nyata}

Kuliah Kerja Nyata (KKN) merupakan salah satu wahana untuk mengaplikasikan teori-teori yang telah didapatkan ke dalam sebuah wujud nyata pengabdian kepada masyarakat [2]. Melalui KKN mahasiswa belajar mengaitkan antara dunia akademik-teoritik dengan dunia empirik-praktis bagi pemecahan permasalahan yang dihadapi masyarakat dapat hidup mandiri dan menolong dirinya sendiri.

\subsection{Ulasan Penelitian Terkait}

Masalah pemetaan lokasi KKN, sebelumnya telah dilakukan dalam penelitian [1], [2], [3], [5]. Penelitian yang dilakukan [5], membahas Sistem Informasi Geografis untuk memonitor KKN Posdaya UAD berdasarkan basis data yang digunakan di Lembaga Pengabdian Masyarakat (LPM) UAD. Sistem akan menampilkan lokasi-lokasi KKN posdaya yang tidak ada perkembangan dalam melaksanakan program kerja yang telah disusun, sehingga akan ada tindak lanjut dari LPM sesuai data yang ditampilkan oleh sistem.

Penelitian terkait lainnya [1], mengkaji tentang pengembangan Sistem Informasi Geografis berbasis teknologi mobile menggunakan Location Based Service untuk mengatasi permasalahan sulitnya mengetahui lokasi dan rute mahasiswa KKN UNDIKSHA secara geografis. Sedangkan penelitian [2], mengkaji perancangan sistem informasi KKN di Universitas Muria Kudus yang bertujuan untuk mengatasi permasalahan dalam pengelolaan data dan penyampaian informasi yang terkait dengan kegiatan KKN. Penelitian [3], mengkaji tentang pembuatan sebuah sistem informasi KKN yang berfungsi untuk mengatur pembagian tim atau kelompok mahasiswa KKN berupa perancangan web based pada Universitas Lampung. Penerapan sistem informasi KKN meliputi proses pembagian tim, penempatan mahasiswa, pembagian Dosen Pembimbing Lapangan, dengan sebelumnya mengetahui program kerja yang akan dilakukan dan kebutuhan desa KKN.

Konsep SIG telah diterapkan pada penelitian tersebut diantaranya: pemetaan lokasi, informasi rute dan Location Based Service. Perbedaan SIG yang dikembangkan dalam penelitian ini, selain menyediakan informasi lokasi KKN dan informasi rute juga menampilkan jarak tempuh dari kampus menuju lokasi KKN, pengaturan hak akses bagi mahasiswa dan Dosen Pembimbing Lapangan (DPL) 
serta penerapan marker untuk menampilkan lokasi desa KKN berdasarkan tema (pendidikan, kesehatan dan daya beli).

\section{METODOLOGI PENGEMBANGAN SISTEM}

Pengembangan sistem yang diterapkan pada penelitian ini yaitu menggunakan metode Prototype [6]. Metode prototype yang digunakan terdiri dari Communication, Quick Plan, Modelling Quick Design, Construction of Prototype, Deployment Delivery and Feedback, seperti yang terlihat dalam Gambar 1.

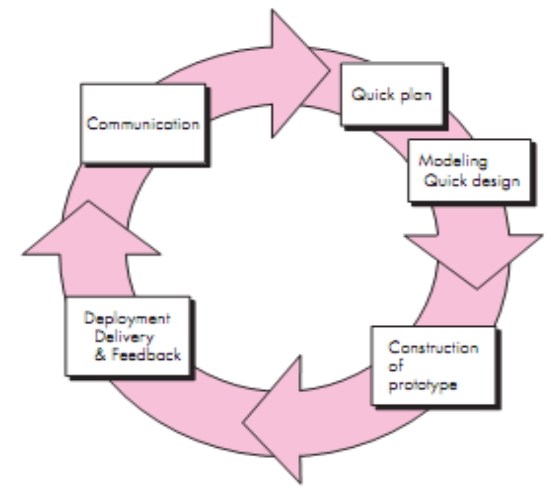

Gambar 1. Tahapan Metode Prototype [6]

\subsection{Communication}

Tahap pengumpulan kebutuhan informasi dilakukan dengan melakukan observasi ke Lembaga Penelitian dan Pengabdian Masyarakat (LPPM) Universitas XYZ. Pada tahap ini informasi yang dikumpulkan diantaranya: data lokasi KKN (desa dan kecamatan), data mahasiswa KKN, data DPL, data tema KKN, data nama kepala desa.

\subsection{Quick Plan}

Tahapan dilakukan untuk menentukan rencana dalam pembuatan prototype. Tahap ini dilakukan dengan menentukan rencana keseluruhan pada pembuatan perangkat lunak.

\subsection{Modelling Quick Design}

\subsubsection{Arsitektur Aplikasi}

Arsitektur aplikasi yang dibangun menjelaskan proses yang digunakan pada sistem informasi geografis penyebaran lokasi KKN dengan melibatkan semua pengguna yang berinteraksi dengan sistem.

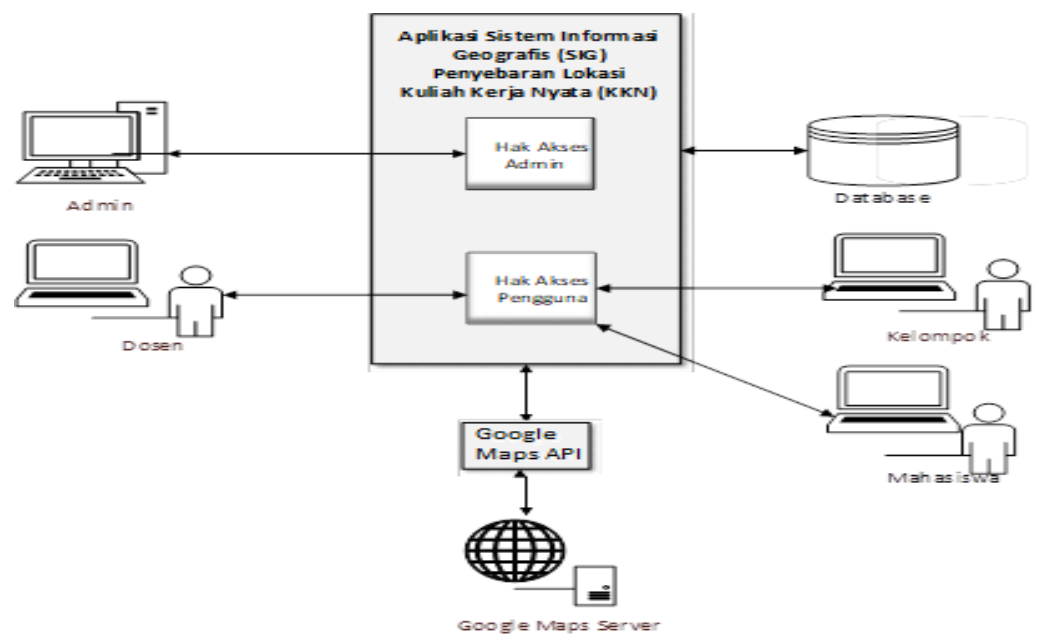

Gambar 2. Arsitektur Aplikasi 
Gambar 2 arsitektur aplikasi, menunjukan Google Maps API menjadi jembatan bagi aplikasi sistem informasi geografis penyebaran lokasi Kuliah Kerja Nyata (KKN) untuk mengakses Google Maps Server. Pada sistem ini Google Maps API digunakan untuk membantu memetakan lokasi KKN dan informasi rute juga menampilkan jarak tempuh dari kampus menuju lokasi KKN, pengaturan hak akses bagi mahasiswa dan Dosen Pembimbing Lapangan (DPL) serta penerapan marker untuk menampilkan lokasi desa KKN berdasarkan tema (pendidikan, kesehatan dan daya beli).

\subsubsection{Pemodelan Data}

Pemodelan data adalah suatu metode yang digunakan dalam menentukan dan menganalisis persyaratan data yang diperlukan untuk mendukung proses pada aplikasi yang akan dirancang.

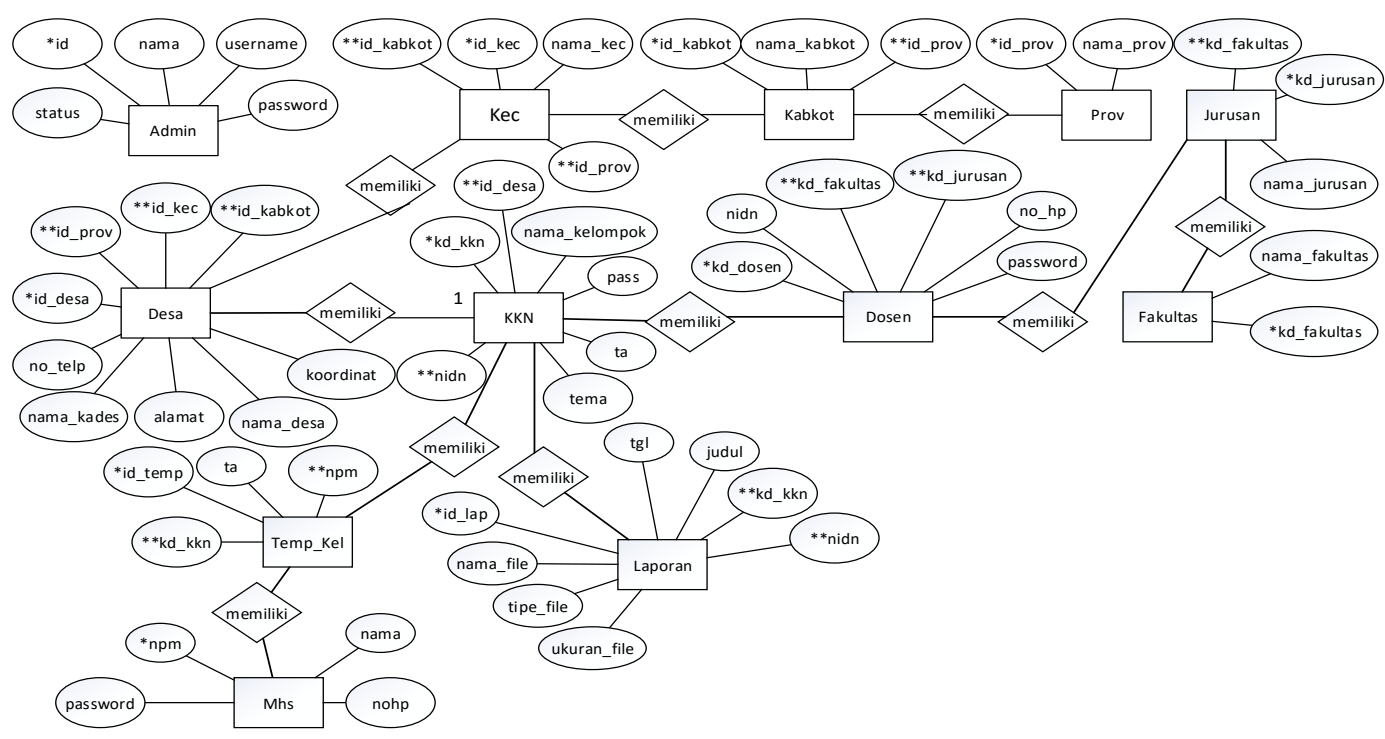

Gambar 3. Entity Relationship Diagram (ERD)

Gambar 3 menampilkan Entity Relationship Diagram (ERD) untuk SIG pemetaan lokasi KKN. Pada ERD tersebut terdapat 12 entitas diantaranya: admin, kec, kabkot, prov, jurusan, fakultas, dosen, KKN, desa, temp_kel, mhs dan laporan.

\subsection{Construction Of Prototype}

Tahap construction merupakan tahap implementasi atau pembangunan perangkat lunak berdasarkan rancangan yang telah dibuat sebelumnya. Pada tahapan ini dibuat aplikasi SIG dengan menggunakan bahasa pemrograman berbasis web dan pemanfaatan Google Maps API yang berintegrasi dengan database.

\subsection{Deployment Delivery And Feedback}

Tahap evaluasi, pengujian dilakukan dengan menggunakan metode pengujian Black-Box. Pengujian dilakukan pada interface perangkat lunak dengan memperlihatkan bahwa fungsi-fungsi bekerja dengan baik. Pengujian dilakukan dengan tujuan untuk mengetahui perangkat lunak berjalan sesuai dengan yang diinginkan atau tidak. Pengujian dilakukan dengan memasukkan data yang valid dan data yang tidak valid untuk melihat respon yang diberikan oleh aplikasi dilihat sudah atau tidak sesuai.

\section{HASIL DAN PEMBAHASAN}

\subsection{Implementasi Perangkat Lunak}

Tahap ini memperlihatkan hasil dari perancangan antarmuka yang telah diimplementasikan ke dalam program yang dirancang. Berikut perancangan antarmuka dari aplikasi SIG penyebaran lokasi KKN yang telah dibuat. 
a. Halaman Pencarian Lokasi KKN

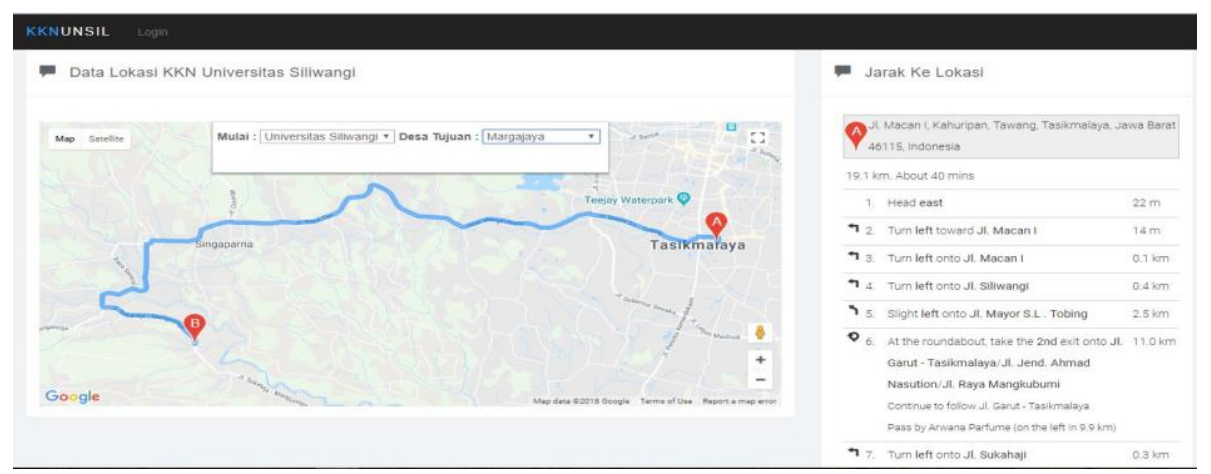

\section{.Gambar 4. Halaman Pencarian Lokasi KKN}

Gambar 4 halaman pencarian lokasi KKN diatas menunjukan peta pencarian desa lokasi KKN beserta detail petunjuk arah dari kampus Universitas XYZ menuju desa lokasi KKN.

b. Input Data Lokasi Desa KKN

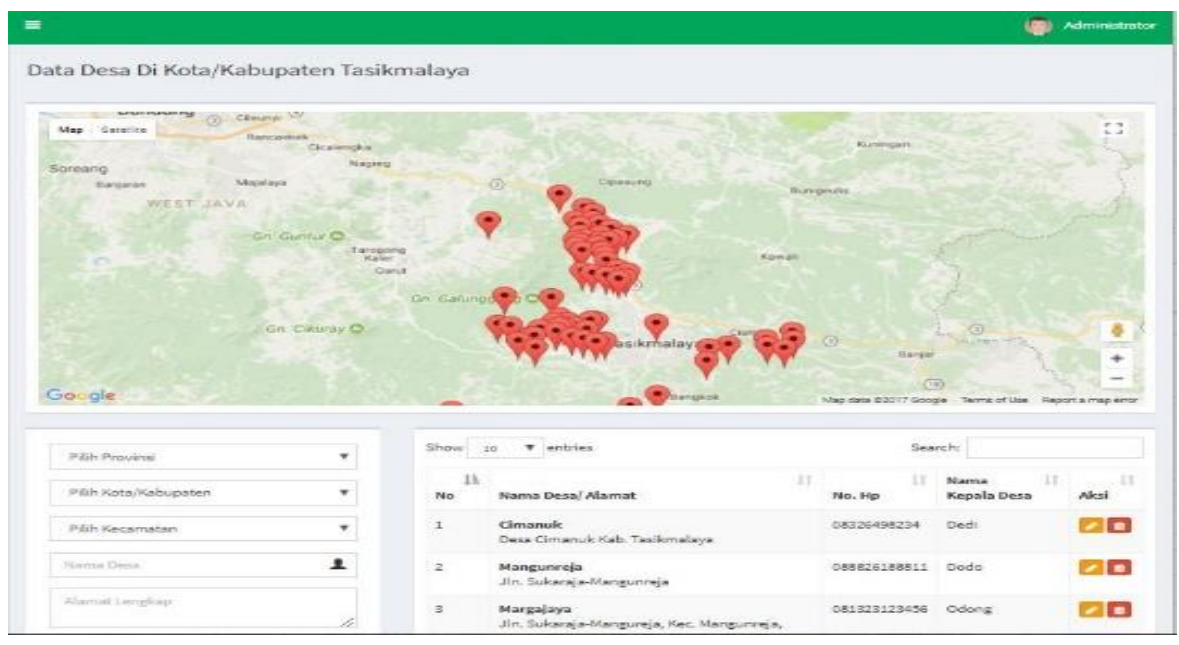

Gambar 5. Halaman Input Data Lokasi Desa KKN

Gambar 5 halaman input data lokasi desa KKN menunjukan halaman data desa dengan menampilkan fitur peta dengan marker desa yang terdaftar sebagai desa lokasi KKN, form pendaftaran desa lokasi KKN dan tabel desa yang telah didaftarkan sebagai desa lokasi KKN.

\subsection{Kelebihan Dan Kekurangan}

Kelebihan pada aplikasi yang telah dibangun sebagai berikut:

a. Aplikasi Sistem Informasi Geografis penyebaran lokasi KKN yang telah dirancang mempunyai fitur tema marker.

b. Aplikasi Sistem Informasi Geografis penyebaran lokasi KKN dapat menampilkan informasi lokasi KKN secara visual berdasarkan tema KKN.

Kekurangan pada aplikasi SIG yang telah dibangun:

a. Penyebaran lokasi KKN yang dipetakan hanya dapat menunjukan satu jarak atau rute dari lokasi pengguna. Karena tidak menggunakan global positioning system (GPS).

b. Aplikasi SIG penyebaran lokasi KKN yang telah dibangun belum responsif untuk bisa dijalankan pada platform mobile sehingga aplikasi tidak dapat diakses dimanapun dan kapanpun oleh pengguna. 


\section{KESIMPULAN}

\subsection{Kesimpulan}

Berdasarkan hasil penelitian yang telah dilakukan dapat diambil kesimpulan sebgai berikut:

a. Telah berhasil dilakukan perancangan aplikasi Sistem Informasi Geografis (SIG) yang dapat memetakan pelaksanaan lokasi KKN sebanyak 91 desa.

b. Telah berhasil merancang aplikasi Sistem Informasi Geografis (SIG) yang dapat menyediakan akses bagi 281 Dosen Pembimbing Lapangan (DPL) dan 2178 mahasiswa untuk mengetahui desa lokasi KKN.

c. Telah berhasil dilakukan perancangan aplikasi Sistem Informasi Geografis (SIG) yang dapat menyediakan informasi rute menuju lokasi desa tempat pelaksanaan KKN

\subsection{Saran}

Pada penelitian ini tentunya banyak kekurangan yang ditemukan, maka dapat diberikan saran-saran yang sekiranya dapat digunakan dan mendukung sebagai acuan pengembangan sistem berikutnya. Saransaran tersebut anatara lain:

a. Sebaiknya dalam pengembangan penelitian yang selanjutnya dilakukan penambahan sistem navigasi berbasis satelit yaitu Global Positioning System (GPS) agar penyebaran lokasi KKN yang dipetakan dapat menetukan jarak atau rute alternatif dari lokasi pengguna.

b. Sebaiknya dalam pengembangan penelitian yang selanjutnya dilakukan perancangan aplikasi dengan platform mobile agar pengguna dapat mengakses aplikasi dimanapun dan kapanpun.

\section{UCAPAN TERIMA KASIH}

Penyelesaian jurnal ini mendapat banyak pengerahan dan dukungan dari berbagai pihak oleh karena itu penulis mengucapkan terimakasih kepada pembimbing yang selama ini sabar membimbing dan memberikan pengarahan dalam menyelesaikan penelitian ini, rekan seperjuangan dan kedua orangtua serta saudara kerabat yang selalu memotivasi sehingga penelitian ini dapat selesai.

\section{DAFTAR PUSTAKA}

[1] K. R. Arthana and I. K. Purnawarman, "Pengembangan Sistem Informasi Geografis Kuliah Kerja Nyata (KKN) Undiksha Berbasis Teknologi Mobile dan Location Based Service".

[2] G. Fandatiar, Supriyono and F. Nugraha, "Rancang Bangun Sistem Informasi Kuliah Kerja Nyata (KKN) Pada Universitas Muria Kudus," Jurnal SIMETRIS, Vol 6 No 1, pp. 129-136, 2015.

[3] R. Saputra, "Sistem Informasi Geografis Pencarian Rute Optimum Obyek Wisata Kota Yogyakarta Dengan Algoritma Floyd-Warshall," Jurnal Matematika Vol.14, No.1, pp. 19-24, 2011.

[4] P. Setiaji, "Sistem Informasi Geografis Industri Di Kabupaten Kudus," Seminar Nasional Teknologi Informasi \& Komunikasi Terapan (SEMANTIK), pp. 235-240, 2012.

[5] D. A. Sumarto and T. Setiadi, "Sistem Informasi Geografis Monitoring KKN Posdaya Universitas Ahmad Dahlan Berbasis Google Maps API," Jurnal Sarjana Teknik Informatika, vol. II, no. 2, pp. 1248-1256, 2014.

[6] R. S. Pressman, Software Engineering: A Practitioner's Approach McGraw-Hill higher education McGraw-Hill series in computer science, California: McGraw-Hill Education, 2010.

[7] A. I. Gufroni, N. Hiron, A. N. Rachman and Y. A. Malik, "Implementasi Google Maps API dalam Aplikasi Mobile Penghitung Jarak Aman dari Dampak Kemungkinan Letusan Gunung Galunggung," Seminar Nasional Aplikasi Teknologi Informasi (SNATI), pp. B-12-B-16, 2013.

[8] M. Rouse, "https://whatis.techtarget.com/," TechTarget, Februari 2013. [Online]. Available: https://whatis.techtarget.com/definition/Google-Maps. [Accessed Desember 2017]. 